\title{
An empirically testable causal mechanism for divine action ${ }^{1}$
}

\author{
Arlyn Culwick \\ Independent Researcher \\ Cape Town, South Africa \\ arlynculwick@outlook.com
}

\begin{abstract}
A form of special divine action often considered central to the everyday experience of Christianity is that of a personal interaction with God. For example, in The Second Person Perspective in Aquinas's Ethics, Andrew Pinsent characterises this interaction in terms of mutually empathic relations that serve to "infuse" virtues and other attributes into a person. Such interaction requires that causal relations exist between a necessary being and the contingent universe. This paper addresses a central problem of special divine action: that the empirically identifiable causes of physical events are modally ill-suited for (and epistemically distinct from) the action of an eternal, non-composite, necessary being. Accounts of what brings about physical events are standardly empirical accounts, grounded upon experience of the world.

In contrast, accounts of how God acts are standardly non-empirical exercises of reason. But as a result, theories about the causality of divine action usually bear no clear relation to the empirical causal modes that, judging by our experience, function to bring about events which God somehow also causes. This is a modal problem in the causal relations of divine action. To solve this problem, I make an (empirical) distinction between material and merely intelligible mind-independent being. From this develops an account of a novel type of causality definitively clarified by the scholastic philosopher John Poinsot, extrinsic formal specification, which is as empirically observable as it is amenable to speculative reason, particularly sacramental and Trinitarian theology.
\end{abstract}

\section{Keywords}

divine action; kenosis; empirical method; semiosis; Ralph Austin Powell

1 This paper started life at the Ian Ramsey Centre's conference on special divine action, Oxford University, July 2014. After years in gestation, its argument matured to the point of scientific proof, at which it was delivered at the Stellenbosch Faculty of Theology's conference, "Theology from Below," 28 March 2019. 


\section{Introduction}

I have intended to perturb the reader with the title of this article, who, I anticipate, is likely to be disinclined to take seriously even the most reputable claims of the occurrence of divine action, let alone a claim as startling as the one to be made in this essay, namely that the action of God theistically taken (a being outside of time and who does not move from potency to act) is in fact empirically testable. The argument for this claim is chiefly concerned with the nature of relations. Now the question of the knowability of divine action always concerns at least two relations: the (presumed) relation of God to the universe (or something in it), and some further relation by which we might attain knowledge of the former relation. In The Second Person Perspective in Aquinas's Ethics (2012), ${ }^{2}$ Andrew Pinsent characterises personal interaction with God (for example, the commonplace activity of daily prayer) in terms of relations of joint attention, that is, the activity of jointly attending to some object ${ }^{3}$ while also maintaining an awareness of the other's stance toward the object. Awareness of God's stance here is, I take it, understood to be a product of joint attention in a manner similar to the gaining of awareness of any other person's stance. But can this awareness qualify as knowledge?

In dramatic contrast to this trust in the experience of everyday relating is a prevailing scepticism about the knowability of divine action, which appears to be attributable principally to the influence of David Hume, whose view in $O f$ Miracles $^{4}$ has acquired a central influence in the literature. ${ }^{5}$

2 Andrew Pinsent, The Second-Person Perspective in Aquinas's Ethics (New York: Routledge, 2012).

3 Ibid., 42-43.

4 David Hume, An Enquiry Concerning Human Understanding. Edited by Tom L. Beauchamp. (Oxford: Oxford University Press. 1999 [1748]), Section X.

5 The University of Oxford's Special Divine Action Project has produced an influence map of a great number of sources on the subject of divine action. Hume's influence is singular. The following image uses "trace" mode to reveal the extent of Hume's influence (including those he provoked) (Special Divine Action Project 2020) 


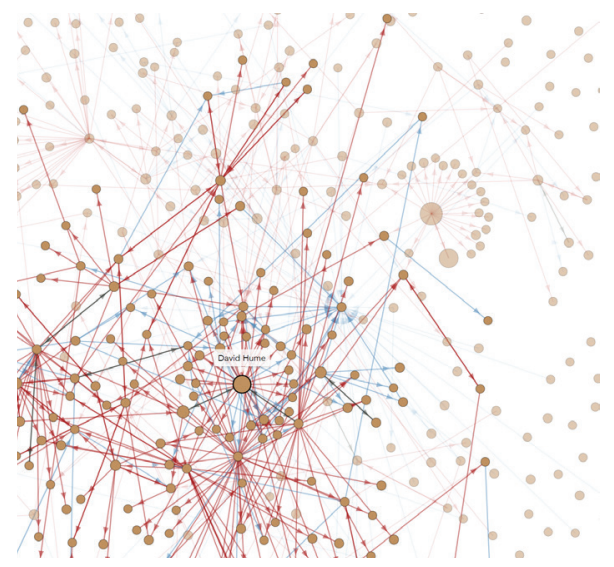

Moreover, this effect appears not have survived the repudiation of traditionally popular interpretations of Hume as having made a sceptical argument against miracles, because it seems that his position is unweakened in practice even on a moderate interpretation of Hume. For example, in a recent book, ${ }^{6}$ Robert Fogelin, a prominent apologist of Hume, makes a compelling argument that Hume does not rule out the possibility of miracles a priori but instead holds for a relative weighing up of probabilities for and against a miracle. ${ }^{7}$ Now while this appears to avoid successfully a common charge of circularity ${ }^{8}$ against Hume's position (namely that Hume begins by assuming that laws of nature do not admit of exceptions, from which it would follow a priori that miracles cannot occur), nowhere in this extended treatment of Hume and of some of his recent interpreters is the notion that "a miracle is a violation of the laws of nature" 9 explored, apart from consideration of whether Hume is a necessitarian, a regularist, or both concerning laws of nature. ${ }^{10}$

6 Robert Fogelin, A Defense of Hume on Miracles, (Princeton University Press, Princeton and Oxford 2003).

7 Ibid. Ch. 1.

8 Ibid., 19.

9 Ibid., 14.

10 Ibid., 17-19. 
While this is hardly the first essay to take issue with Hume's definition of miracles, the fact that Hume's definition is not at the very centre of the debates that his apologists engage with, ought to be surprising given the nature of the subject matter. The subject is miracles traditionally taken as acts of a theistic God. This, I would think, engenders at least three difficulties for Hume's definition on grounds of its inadequacy to treat of the subject. Firstly, it would hardly suffice to define a miracle in terms that both presuppose the action of God and imply that any miracle is a violation of laws that God simultaneously sustains. Not only would this impose a paradox or perhaps even inconsistency onto divine action, but it introduces this perplexing conceptual arrangement a priori, which is inconsistent with Hume's empiricism (which instead requires their derivation on the basis of experience). Secondly, a "law of nature" (whether taken epistemically as "constant conjunction" or as real patterns in nature, or both ${ }^{11}$ ) does not admit of any obvious means for God to act (granted, this is likely a problem for Enlightenment-style thinking in general, not only for Hume in particular). It is thus problematic that a matter presupposing divine action is cast in terms that make no room for it a priori, ushering in time-worn problems of God "meddling" with creation, and alleged "double causation." 12 Thirdly, without supplying a radically different framework for approaching divine action, it might seem, under the prevailing perspective, modally inconsistent to apply empirical methods to a theistic God, a necessary being outside of time. By doing precisely this in this article, I might seem to be committing what Ryle ${ }^{13}$ famously terms a "category mistake," since a theistic understanding of God as a necessary being does not appear amenable to discussion in empirical terms applicable to causally contingent objects. However, I assure the reader that the expected modal inconsistency only occurs when discussion is wrought from the insufficiently general materials of philosophical modernity. Moreover, if the preceding remarks about Hume's definition

11 Don Garret, Cognition and Commitment in Hume's Philosophy (New York and Oxford: Oxford University Press, 1997), 152 in A Defence of Hume on Miracles, 27-28.

12 C.f. Michael J Dodds, The Doctrine of Causality in Aquinas and The Book of Causes: One Key to Understanding the Nature of Divine Action (Notre Dame, Indiana: Jacques Maritain Center: Thomistic Institute, 2000).

13 Gilbert Ryle, The Concept of Mind (Chicago: University of Chicago Press, 1949). 
of miracles are accepted, then in order to approach the problem at all specifically, in order that our consideration of the nature of divine action ${ }^{14}$ might be free of a priori bias on the basis of foregone doctrines or definitions hostile to those on one or another side of the debate - a new approach is required that is amenable to the action of a theistic God - but that also avoids intractably speculative approaches to divine action that cannot be made amenable to empirical verification. Hence, to satisfy the concerns of those sceptical about the reality of divine action, the hypothesis to be offered here (a) employs only a causal mode acceptable to science, and (b) avoids modal inconsistency by resting upon a foundation both general enough to be indifferent to the modality of its terms, and amenable to empirical verification. This foundation I derive principally from the work of John Poinsot in the 17th century, and partly from Ralph Austin Powell, in my view his most major $20^{\text {th }}$ century discoverer. ${ }^{15}$ The structure of this paper is as follows: first, I will imply, by thought experiment, that real relations are fundamental to a universe and constitutive of all objects. Second, I will show on the basis of common experience that real relations commonly embody their objects. Third, I will show how God's nature (speculatively taken) is expressed in relations (empirically taken). From this it would follow that every experienceable relation can be truly experienced as embodying God's nature, if God exists. Finally, it remains to construct this in publicly verifiable terms, so that it is not merely a speculative idea resting on private ("subjective") experience, but a scientifically knowable fact. ${ }^{16}$

14 I have in mind Aquinas's theory, which draws upon the Neoplatonic Book of Causes. In order to permit empirical verification of this theory, one would need to observe several orders of speculated causality arranged hierarchically above those of the empirical realm, making them unobservable by definition.

15 John Deely attributes to Powell the rediscovery of the causality proper to the action of signs as established originally and systematically by John Poinsot in 1632. (John Deely, "The Grand Vision," in Transactions of the Charles S. Peirce Society 30, no. 2 (1994): 371-400.)

16 It would be remiss of me to omit from the introduction to this article the fact that it embodies a concern about contemporary analytical philosophical writing. The paper ventures an answer to a "big question," and thus unavoidably makes grander or more general claims than is typical of essays in the analytical style. Even though this may be put some readers off, I have done so deliberately, as a result of forming the following stance on this matter:

Contemporary academic (particularly analytic) philosophy loses out on a great deal by emphasizing detailed analysis and rigour at the expense of (a) systematic thought 


\section{What kind of causality would suffice to explain special divine action?}

From a modern standpoint, there is a core perplexity to divine action. On the side of the known universe, for a theistic God to interact with people or anything else in the universe, causal relations must obtain. For a human being to experience second-personal relationship with God, or for God to alter anything in one's life - or in general for us to experience special divine action at all - the effect of God's action would be an empirical one. But what sort of cause could operate in the material, temporal, contingent, empirical world, yet also be consistent with the action of a nonmaterial, eternal, necessary being? On the side of God's nature, God's acting would not be empirical. It would not be temporal. It would not be material. God would not undergo change, in the sense that change implies a movement from potency to act, since God is pure act. But what sort of causal relation could accommodate such a radical difference between cause and effect? At the very least, a suitable one would have to be indifferent to the ontological status of its terms.

and (b) directly tackling "big questions" that tend to be difficult to answer. Worse still, my impression of typically analytical essays is all too frequently that they sacrifice the activity of philosophising in favour of the merely scholarly tasks and technical methods attendant upon good philosophising. By "philosophising" I mean directly the activity of finding answers to various questions, including and perhaps especially answers that do not engender inconsistencies, contradictions, or paradoxes in other areas of inquiry. To philosophise, therefore, is necessarily creative and synthesizing, over and above the requirements of good scholarship and of arguing soundly from premises to conclusion. But in my experience, these latter activities very often overshadow the activity to which they are ordered, namely, "finding answers." Now since I think that this is a widespread practice - perhaps the norm in analytical philosophy - it appears to me that the greater value of philosophy itself is commonly sacrificed in favour of a focus on micro-details and on tackling narrowly-focused problems upon which one's technical skill may be well executed. In its pure form, the problem is that the ends are bent to serve the means, and not vice versa.

Judging by appearances, to philosophise at all is an ambitious undertaking with necessarily lofty aims; to shrink from this in favour of more humble goals would probably be an advantage to one's philosophical career, but it would not result in better philosophy. In reaction to this trend, this article represents my strong preference to order scholarship and technical ability to the end of philosophizing, and I hope that it encourages others in the field not to allow means to overshadow our common end. 


\section{Universes}

Thus, the first task of this essay is to introduce a perspective under which this modal problem does not arise. The perspective I offer is one implied by the action of signs, or semiosis. Consider the following thought experiment:

Attempt to imagine a collection of things, none of which can have any kind of relation to each other. In order to construct this experiment correctly, do not attempt, in one breath, to visualise a collection of things that can have no relation to each other. Rather, by a simple process of abstraction begin to consider such a scenario, and as soon as you think of any respect in which the things might be related, rule it out. Are they related in space? No. Do they both have shape? They could not. Do they both have a surface? No. And so forth.

Now in what respect could these things comprise a system? In no respect, since there is no means (not even spatiality) by which the things can be related. There would be nothing over and above their existence by which they could comprise a system.

\subsection{Universes necessarily are systems}

Now a universe is necessarily a system, however scantily related its components might be, or else there would be nothing to make it an entity in its own right, over and above its components. If one were to argue the contrary, the only basis by which a universe could be anything would be by force of describing it in language or in thought. As such, however, it would be a mere nominalism. Without a mind-independent basis intrinsic to the universe in question, there would be no way in which a universe could be anything in its own right.

Therefore from the perspective of being a universe and not just a relationless "heap" there is no difference between there being no things at all and each thing being nothing to any other thing: in either case the outcome is identical: since a universe requires some way of relating - some "principle of unity" - there would be no way to be a universe. Therefore, a universe does not arise if things can have no relation to each other. 


\subsection{Things necessarily are systems too}

Let us now turn our focus onto the things themselves in the thought experiment. For anything to be a thing, it would have to be a system of interactions in its own right. If you are in any doubt about this, it appears to be the case for the actual universe. For example, the following regress seems to occur in physical sciences, which reduces "matter" to relations pervasively:

1. A theory - say, gas laws - explains (and predicts the behaviour of) a thing or system of things in terms of relations between aspects, components, or attributes it has (in the case of gas laws, molecules).

2. Since relations necessarily have terms, the things or systems embodying these terms can in principle be empirically investigated, resulting in a theory that describes their internal relations. For example, molecules are in fact atoms or ions interacting.

3. These new relations' terms (i.e. the atoms) are investigated, resulting, of course, in a further theory that describes the behaviour and constitution of the thing in question in terms of further relations between new terms, ad infinitum.

4. Thus, gases are relations between molecules, which are relations between atoms, which are relations between electrons, protons, and/ or neutrons, which are relations between quarks, leptons, and bosons.

The latter are called "fundamental" particles not because they are known to be indivisible "building blocks" of reality, but merely because it is unknown whether they have parts in relation. It is possible that at smaller scales there are no further parts or "particles" (that is entities identifiable by spin, energy level, etc.), but this is not to say that there would be nothing; at the most fundamental layer, there would be something - perhaps simply a vague fuzz of relations between relations, with no term having intrinsic specification (an intrinsic nature) of any kind. ${ }^{17}$

17 Such a scenario is theorised under the name "quantum foam" to be interspersed by particles (and their complimentary antiparticles) momentarily popping into existence and then annihilating themselves, giving spacetime a granular texture that otherwise would be "smooth", that is to say, having nothing to cause enough disturbance to quantise out a particle. This scenario suggests a thoroughgoing fundamental 
Since my thought experiment is one in which there are no relations, it follows that it could contain no things, since it appears that being a thing requires having relations. Therefore, this scenario can feature neither things nor a universe. In other words, the scenario contains "nothing" at all.

From this we can deduce - to put it informally - that something is only something if it is something to something else. Apart from this, it cannot be actual.

\section{Real relations}

\subsection{Real relations are the principal object of scientific study}

Real relations appear fundamental to a universe and constitutive of all objects. Now it also happens that real relations of a specific sort are the principal object of scientific study. To summarise briefly the view of Ralph Austin Powell, he claims that scientific method does not reveal the intrinsic nature of things: ${ }^{18}$ The effects predicted by science are of the nonmaterial, purely formal, nature of a specification of form (e.g. velocity, position, etc.) in future on the basis of data of a present state; but a future state such as this "lacks an intrinsic formal cause [and ... ] any intrinsic nature. Hence, temporal relations have only got extrinsic formal specification." ${ }^{19}$

Powell gives an example of how the relation termed "extrinsic formal specification" in the scholastic literature functions in the growth of scientific knowledge: ${ }^{20}$

it is precisely the function of extrinsic formal causality to displace the agent and final causes by a more elementary cause ... Thus, the solar system is explained as a mechanism specified by extrinsic formal causes without needing any explanation by agent causes (let alone by final causes which have not been recognized by science

relationality at scales smaller than fundamental particles, which lacks the stability to sustain a mechanism to produce "stuff" reliably.

18 Ralph Austin Powell, "Epistemology's Minimal Cause as Basis of Science," in Semiotics 1988, edited by Terry Prewitt, John Deely and Karen Haworth (New York: University Press of America, 1989), 183.

19 Ibid. 182-3.

20 Ibid., 186. 
since the $17^{\text {th }}$ century). For, Einstein's general relativity precisely eliminated gravitational forces [under the rationale of an agent cause] from explanation of the solar system, by substituting the curvature of space-time for gravitational forces. ${ }^{21}$

Now gravitational forces are agent causes, whereas the curved space-time that governs the path of the earth around the sun is an excellent example of extrinsic formal causality.

In other words, scientific investigation involves a process where the agent causality of "material" bodies in an earlier theory is surpassed by a later theory employing extrinsic formal causes, on grounds that the latter is knowable and testable, while the former constructs the same object of experience along the lines of an unknowable intrinsic nature. As such, the employment of extrinsic formal causes permits the growth of scientific knowledge, by rendering knowable what is unknowable under a prior model.

\subsection{Real relations are directly experienced}

If it is accepted that extrinsic formal causality underpins scientific knowledge, it appears that it also underpins the experiences that verify scientific theories, at least in the sense that unless we are physically affected by real external things, we would merely be experiencing mind-dependent unrealities, instead of making observations of mindindependent realities. We are thus primarily passive to real things, where they extrinsically specify aspects of the form our experiences take.

Now Powell observes that to be passively affected is to be in a causal relation of agent to patient, and what we directly and immediately experience is these relations, not the object itself. ${ }^{22}$ To give an example, consider a glass of water in front of you. Pick it up, drink from it, use it. Your experience of the glass is not the hypothesised immediate knowledge of God, but rather one mediated by your senses. It is scientifically theorised that attributes

21 Stephen Hawking, A Brief History of Time: from the Big Bang to Black Holes (New York: Bantam Books, 1988), 29-30, in Powell, “Epistemology's Minimal Cause as Basis of Science."

22 Ralph Austin Powell, "From semiotic of scientific mechanism to semiotic of teleology in nature.” Semiotics (1986):299-300. 
of the glass - say, its reflection of light in various frequencies - serve to stimulate your visual system, the resulting electrochemical signals from which serve as grounds for you to perceive and cognitively identify the glass. That is, you are in relation to the glass. Now it is the relation that you directly experience, in the sense that you do not directly experience the intrinsic nature of the glass itself, but some respect in which the glass affects you. Nor do you directly experience the theorised intermediate steps (the electrochemical signals and light frequencies); these can merely be inferred from what is implied by directly experienced relations. In summary, experience of at least some relations is direct, whereas experience of objects requires the mediation of relations.

\subsection{Real relations can embody their objects}

Moreover, real relations commonly embody the thing related to. For example, directly experiencing your relation to the glass embodies the glass, for you, because we do not typically draw our attention to the mediating steps or the properties of the glass. Instead, we typically just use glasses, and so our experience is typically of the glass itself, not of mediating processes. Now these mediated experiences of the glass (a) are your only and total experience of the glass, and (b) form a familiar, habituated understanding of glasses that has matured to the point of accurately modelling the object's nature for your purposes and thus accurately presenting it to you. Because of (b), your understanding is a good model (for the purposes you have) of the glass in itself. Because of (a), there is nothing in your experience of the glass to unsettle your understanding of it. But for (a) and (b) to obtain is just what it means for a sign to participate in the nature of its object. After all, the sign (your experience of the glass) really does present real properties of its object (the glass) to you, at least to the extent that you are really relating to it on a regular basis permits your understanding to come to grips with properties that matter for your purposes (e.g. its ability to hold water, and its brittleness when dropped). Thus, its nature is what the object's nature (partially) is. This is to say that the extent to which a sign brings something of the nature of its object to you, it embodies its object. 


\section{What relating comprises}

If relations are fundamental to the universe and are what we experience directly, and if they support embodied experience, then if I can show how God's nature is expressed in them, it would follow that every experienceable relation is capable of supporting experiences of the world as embodying God's nature. ${ }^{23}$ To show this, I will need to explain how relations function at a more granular level (though the matter of whether these experiences are merely speculative, or are knowable as real experiences of divine nature, will be addressed in a later section).

Consider some object in relation to another object. Formally speaking, the relation occurs between at least one attribute that each object has, and the attributes are required to be strictly correlated in order to relate in a given respect. For example, a relation of parenthood requires one person to possess the attribute of being a parent and another to possess the attribute of being a child. These are "terms" of the relation, such that the relation is "founded" upon the attribute of being a parent and "terminates" at the attribute of being a child.

We learn from Poinsot that there are in fact two correlated facets to each relation between attributes. Since they are correlates in the same relation, they are one phenomenon and thus demand one name. (I will show shortly that it is worthy of the designation "kenosis.")

The first correlate is known as determining ${ }^{24}$ and is the role of a relation's terminus.

23 For the avoidance of confusion, the use of the term "embody" here is not intended to invoke questions concerning God's omnipresence. "Embody" implies the common effect of signification in which the terminus is experienced as caught up in, or bodily present in, a fundament. "Embody" thus makes an epistemic commitment, not a metaphysical commitment in the manner of theism, pantheism, panentheism, and so forth concerning omnipresence.

24 John Poinsot, Tractatus de Signis (1632), edited by John Deely and Ralph Austin Powell (Berkeley: University of California Press, 1985), 166-192 (Book 1, Question 4). 


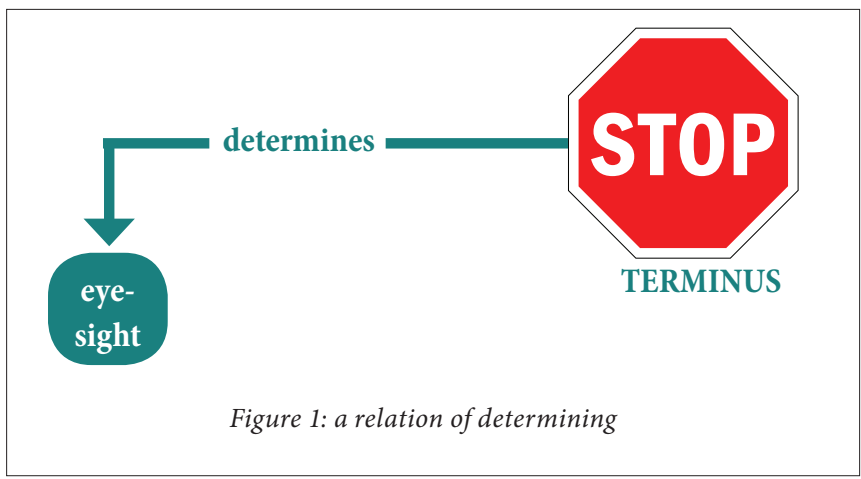

What a terminus does is delimit the scope of possible ways it may be related to. For example, a stop sign cannot terminate the thought that it is rectangular, since it is octagonal. In this way, a terminus determines its fundaments by having a certain nature, which cannot be what it is not, and so cannot support a fundament that is unable to relate to its attributes. Furthermore, determining, thus characterised, is understood traditionally ${ }^{25}$ to be the basic causal mode of objects and an exercise of extrinsic formal

25 Due to most readers' unfamiliarity with the dense terminological system of Poinsot's semiotic, I am (though I lament doing it!) introducing only a minimum of technical material and employing as few technical terms as possible. But it may be clearer to scholars familiar with Poinsot to note that, concerning the object in this example, I do not distinguish between the obiectum movens and the obiectum terminans (166/4-11; 167/10-39 of the Tractatus) and take this distinction to be strictly beyond the scope of this article, since it is unconcerned with object typologies beneath the level of action, and as Poinsot observes (167/45 - 168/7), these two objects coincide in specifying an act:

"St. Thomas says that "an object is related to a passive power as a principle and moving cause," "but it is related to an active power as a terminus and end." "From these two," he says, "an action receives a specific character, namely, from a principle or from an end, that is, a terminus." Therefore St. Thomas thinks that an object of a passive power coincides with an object of an active power in this, that it specifies an act. And finally, in his Commentary on Book II of Aristotle's treatise, On the Soul, toward the end of reading 6: 2 "It is manifest," he says, "that every object is related to an operation of the soul either as something active or as a terminus; but from both is the operation specified." The word "every" here expresses the universal rationale of an object.

I will, however, shortly distinguish "material" and "formal" termini which are these objects' principal roles in relations, respectively. In the current paragraph, in which "determining" is introduced, I invoke concretely - i.e. through the example - how a material terminus "determines" in virtue of its nature the signs that may represent it. 
causality. Finally, this causality is observed by Powell to be the direct object of scientific theory. ${ }^{26}$

The second correlate is known as representing. ${ }^{27}$ It is the role of the fundament and runs in the opposite causal direction to determining. For example, when you see a stop sign, your perceiving of shape represents the octagonally shaped stop sign, and thus are you guided to recognise that it

Here I am following closely Poinsot's remarks about material termini on p.382/4-16 (Appendix C) of the Tractatus:

"the distinction has to be made between the terminus understood most formally in the rationale of an opposed terminus, and the terminus understood fundamentally on the side of the subjective being founding this rationale of terminating. In the former way a terminus concurs in a specification purely terminatively, but not by causing that specification, because so considered it is a pure terminus and simultaneous by nature and in cognition with the relation; therefore as such it is not a specifying cause, because a cause is not naturally simultaneous with but prior to its effect. If it is considered in the latter way, the terminus stands as an extrinsic formal cause and specifies in the manner of an object, and in this way a single specifying rationale of the relation arises from the foundation and terminus together, inasmuch as the foundation contains the terminus within itself by a proportion and power; for it is not relative to a given terminus unless it is a specific fundament, and conversely. In this way, to the extent that they are mutually proportioned, terminus and foundation together bring about a single rationale specifying a relation which postulates both a specific foundation and a specific terminus corresponding thereto."

Later, I introduce the notion of a formal terminus.

26 Ralph Austin Powell, "Epistemology's Minimal Cause as Basis of Science". Edited by Terry Prewitt, John Deely and Haworth Karen. Semiotics 1988. New York: University Press of America, 1989. 180-188.

27 The chief passage followed for this definition is Tractatus de Signis, 26 (Summulae, Chapter 2). As with "determining," only the barest minimum of technical terminology is being introduced here, but it would be more precise to refer not to "eyesight" in the diagram but rather to the experience of seeing, or perhaps to the physical impression upon the visual system. Additionally, scholars of Poinsot may hesitate to accept "representing" as a correlate to "determining" because, for example, the stop sign would represent not only your perceiving of shape, but also itself and the legal command to stop. However, it is clear that "determining" is correlated to these other cases of representing. Poinsot (26/39-42) states that:

"To represent is said of each factor which makes anything become present to a power, and so is said in three ways, namely, objectively, formally, and instrumentally. For an object such as the wall represents itself objectively, an awareness represents formally, a footprint instrumentally."

Now in each case, in order to become present to a power, an object must first determine it, so that the power may then represent it. Hence, "determining always precedes "representing", and of course both must occur before signification can take place. 
is a stop sign. In this way, fundaments represent their termini by having attributes that are taken to embody a terminus due to the terminus being taken to possess those attributes.

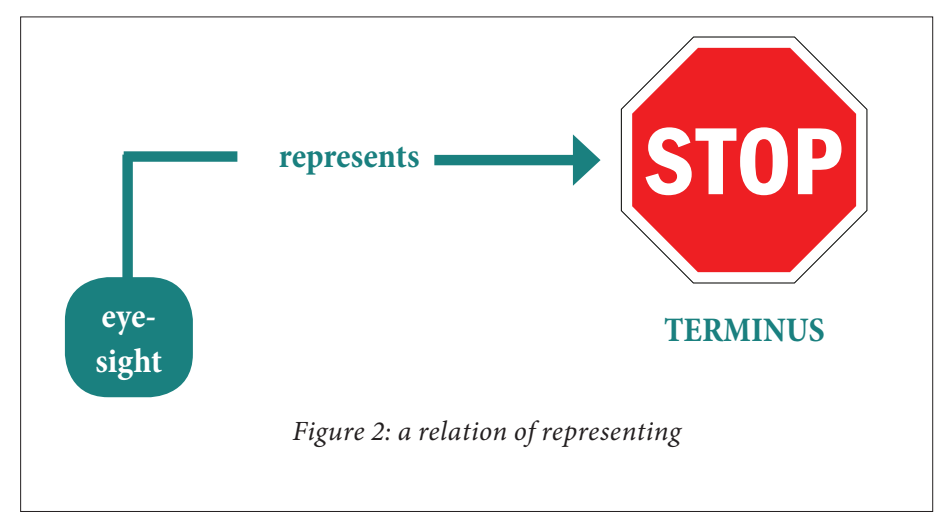

In every relation, determining and representing occur together in a twoway causality, which I will call founding, since it is the defining function of a fundament. For example, provided a driver has recognised a stop sign, it can function to represent to the driver the command to stop. It does so because the rules of the road determine the meaning of a physical stop sign, enabling the sign to represent the rules, and thus to signify the command to stop.

In the examples of the glass of water and the stop sign, in addition to a fundament and a terminus, the intelligent experience of a human being is required for these real relations to arise. There is in fact a third term in every real relation, known as an interpretant, ${ }^{28}$ to which a fundament and terminus are seen to relate, such that an interpretant is actually affected by their relating. Moreover, interpretants need not be human beings; I have shown elsewhere ${ }^{29}$ that biological organisms and inanimate objects are equally capable of functioning as interpretants. The two facets of

28 Charles Sanders Peirce, "Lowell Lectures on The Logic of Science; or Induction and Hypothesis: Lecture VII" (1866), W 1:464-465.

29 Arlyn Culwick, ""Machine code for the universe": how the action of signs pervades everything." Academia.edu. [Online]. Available:https://academia.edu/39709311/_ Machine_code_for_the_universe__how_the_action_of_signs_pervades_everything. [Accessed: 14 July 2019] 
"founding" obtain in fact between both a fundament and terminus, and between an interpretant and fundament, producing the triadic nature common to all real relations. ${ }^{30}$

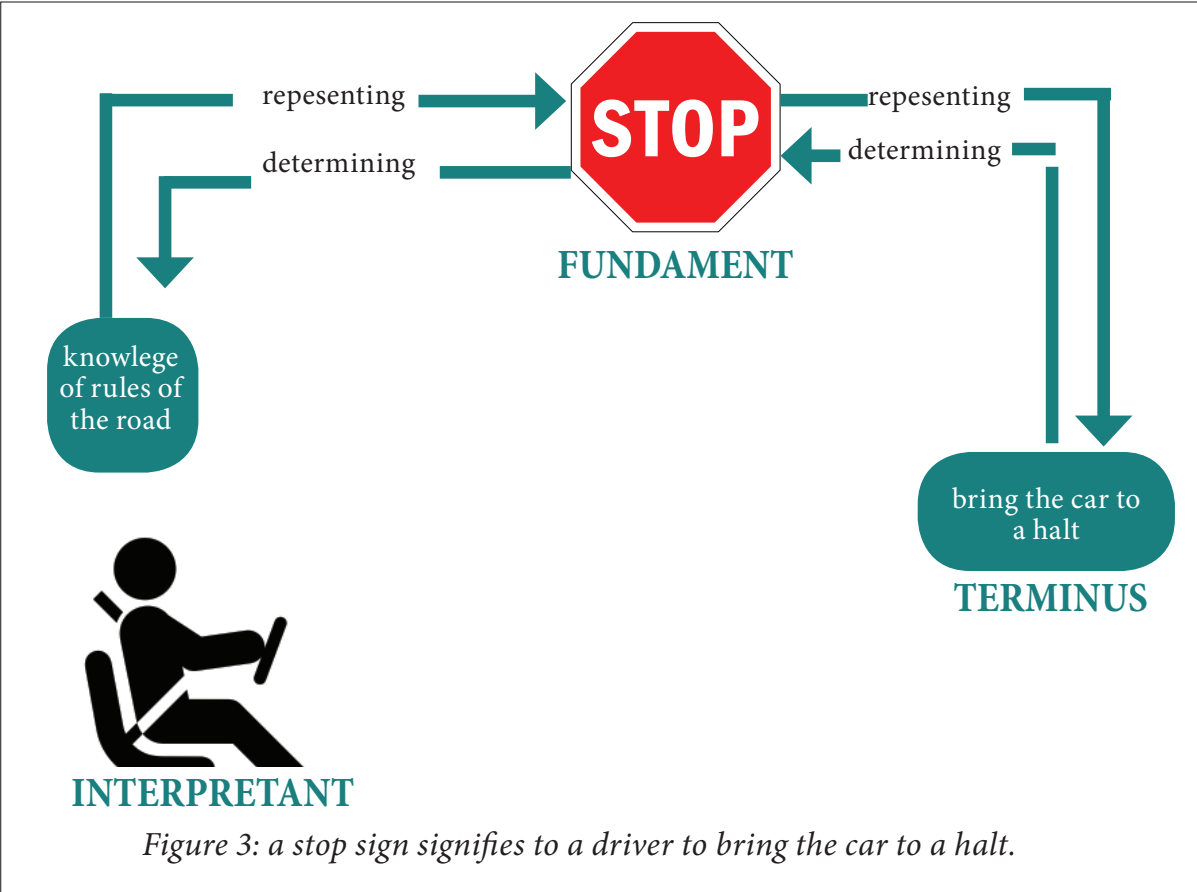

Just as in the example of the glass of water, the command to stop is typically experienced as embodied in the stop sign.

\section{Relating is knowable empirically as kenotic}

Relations have what I will call a "kenotic" character. Kenosis is a term with theological provenance, meaning, in Greek, "an emptying," which

30 And indeed, common to all signs. (All real relations are signs, but not all signs are real relations.) For a more detailed introduction to the nature of real relations, see Culwick, "Machine Code for the Universe". 
traditionally connotes the self-sacrificial character of Christ's love. ${ }^{31}$ For example, committing to a life of poverty in order to serve people in great need is "an emptying" of self, that is, a sacrificing of various potentialities for the good of another. Note, however, that since the applicability of the term "kenosis" is not an empirical matter but a definitional one, I am not required to provide an empirical proof at this point. Rather, I believe it suffices to give an argument from analogy.

In order to draw out the kenotic character of real relations, I will need to sketch, to some minimum of detail, their modes, of which there are three: potential, virtual, and actual.

Consider all possible attributes of everything in a universe, limited only by whether the objects in a universe could actualise these attributes (thus excluding the unreal possibilities of mere imagination, and also all possibilities that just do not happen to be really relatable to any particular object). These are "potentialities" - with which I intend to imply the same physical sense imparted by the term "potential energy." For example, a rock perched on the crest of a hill has a measurable potential energy, which corresponds to its mass and the height of the hill, which suffices for a new attribute - the momentum it can acquire - to be realisable with a certain definite and real "potentiality" (same sense) latent in the physical system. Taken this way, potentialities are almost any kind of property at all, in the sense that they have being as part of the total combinatorial potential for interactions in the universe.

Next, consider attributes inhering in an actual object. These are actualised by whatever circumstance in the universe satisfies a specific respect under which a real relation obtains between a fundament, terminus, and interpretant, as above.

As for virtuality, it is exceedingly common that a merely potential relation (or even an imaginary one) signifies actually. For example, if I am your brother, this is a real relation concerning our provenance. Now if I were to die, you would no longer have a brother. The real relation has fallen away, and only a mind-dependent relation to a memory and a knowledge of our common provenance remains. Yet you would continue, entirely

31 See, for example, John Polkinghorne (ed.), The Work of Love: Creation as Kenosis (Grand Rapids, Mich.: Wm. B. Eerdmans Publishing Company, 2001). 
legitimately, to refer to me as your brother, because the relation remains formally unchanged. That is, it remains founded in the same provenance, it still signifies brotherhood, and it still terminates (at least formally) at me.

In such a case, when you speak of me, your words really signify a brother to every listener, yet the terminus is now unreal, because I no longer exist. Now the definition of "virtual" is to not be some thing, yet to have the actual efficacy of that thing, ${ }^{32}$ and this is precisely the case here: the sign's terminus is unreal, that is, there is no determining correlate on the side of my essence, and so no real relation arises; yet everyone you speak to about me actually experiences you as signifying brotherhood. Hence, a merely potential relation signifies actually.

Such cases are common in real life: histories of real things no longer existing, fiction, misapprehensions, lies, unbuilt designs, and new ideas are all virtual signs, due to the absence of a real relation to their termini. In contrast to potentialities, they are not limited by the real potential in the universe to support relations, but instead need only be imaginable (or otherwise constructible) by any interpretant.

The three modes are derived directly from sign action: actual signs have a fundament, material terminus and interpretant, while potential signs have no interpretant, and virtual signs have no material terminus. Only actualities are sufficient to establish a real relation. Potentialities are merely scenarios in which a relation could arise, while virtualities are subjective to the interpretant, even though other real relations may result from them (for example, when two people converse about one's dead brother, they really relate to one another). ${ }^{33}$

32 Charles Sanders Peirce, The Collected Papers of Charles Sanders Peirce (1958-1966). Electronic Edition (1994), 6.372. See also http://www.commens.org/dictionary/term/ virtual.

33 While virtual signs do not establish a real relation between their terms, they nonetheless signify actually, and may establish real relations consequent upon the act of signifying. I am grateful to Brian Kemple for the following example: if someone were to step off a cliff as a result of believing a bridge to be before them, when in fact no bridge is, they would find themselves in a real relation indeed. The modes, and their tracing of how things become real, is given a fuller introduction in "Machine Code for the Universe," 13-16. 
Now when considered in terms of how things change, or how things come to be, the modes function as a modal filter. That is, the number of elements in the system begins with an infinite plenitude of merely virtual relations to any imaginary or otherwise unreal terminus. This number is then reduced to the latent physical potentialities that are unactualized but terminate at real things, and so are actualizable. Finally, they are again filtered, leaving only real relations - that is, interpreted relations to some material terminus. Being is thus filtered by acts of coming to be in relation.

In the graph below, circled letters are attributes, rectangles are objects, and arrows signify what a given interpretant takes an object to signify. Interpretants (not shown) function to bring attributes from the blue circle into the orange-brown circle, ${ }^{34}$ if not the green circle.

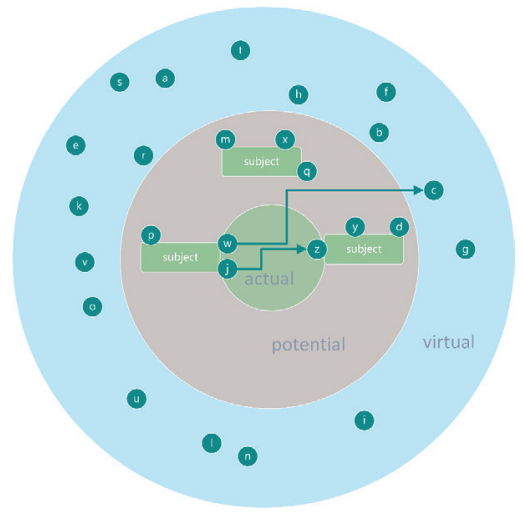

Figure 4: modalities of attributes, and the filtering effect of relations

Modal filtering is trivial to show directly. A rock perched on the crest of a hill, when it is tipped and begins to roll down the hill, begins a process of exchanging potential energy for kinetic energy. That is, formerly potential relations specified by its distance from a resting place on the earth, and

34 The reader may notice that I have stated earlier that potentialities have no interpretant, which may appear inconsistent with the claim here that interpretants function to bring attributes from the blue (virtual) circle tothe orange-brown (potential) circle. Some explanation is due. The way that this occurs is through the real effects of virtual signs: it is by their effects' reality they engender new potentialities for relating, thus new attributes in the orange-brown circle. 
the earth's mass, become actualised in the form of momentum. ${ }^{35}$ As such, indefinitely many other potentialities are filtered, such as the rock undergoing a reaction with the soil it rests on, or perhaps functioning as a landmark for people navigating the landscape.

As for virtuality, if a group of children dare each other to roll rocks down a hill, they imagine the prior potential scenario. Here, the rock's potential relation now has a real interpretant, whereas in the prior scenario it was a mere physical potentiality. Yet in an act of imagination, the rock's kinetic energy is not yet actualised, and so the imagined act does not yet have a material terminus; it only signifies virtually. The children may just as well imagine drawing on the rock, using it as a fortress, or even something that is not a latent potentiality the physical universe, like it being an egg due to hatch some formidable monster. In such cases, a rich array of possibilities abounds, unfettered by the real, and as-yet unfiltered by their actually rolling the rock down the hill.

\subsection{Kenosis}

Now it is easy to show how modal filtering is kenotic in terms of the correlated aspects of relations introduced above, namely "determining" and "representing." I will begin by illustrating it in a human and familiar setting: an act of loving. Love necessarily involves two aspects: an aspect of self-sacrifice on the part of the lover, and an aspect of hospitality or receptivity on the part of the beloved. For example, say I take time out of a busy morning to wash the dishes for my wife. The act involves a sacrifice of my time and effort, and it involves my wife's benefitting from it. Now in order for the act to be loving in a manner that sign action implies is necessary to actualise a real relation of love between us, it is not only

35 I exclude from this scenario the possibility of someone conceiving of it as liable to be converted into kinetic energy, since this would render it virtual, not potential. While an act of conceiving is required for the reader to understand the scenario, it is not required for rocks perched on hills. Their potential to roll down hills unobserved remains a potentiality, not a virtuality. That said, whenever one actually rolls down a hill, the actualisation of its potential has an interpretant regardless of the presence or absence of an observer: insofar as its rolling is a matter of its momentum being actualised, the fundament of the physical system is the product of its mass and its height above its resting place, the terminus is its acquired momentum, and the interpretant is its impulse, that is, the integral of force over time (I exclude, for simplicity, other aspects like friction). 
necessary for me to have done the act in love, but also for my wife to actually be loved - that is, for her good to be attained - by the act. This entails a relation characterised by determining and representing, as above: the former loves, and the latter possesses the capacity to be loved in the manner that the former loves.

It might be objected that the passive term is not necessary. For example, would it not be love even if my wife took offense, due to her feeling that I had, say, washed the dishes as if to imply that she had been neglecting them? In response I assert that my act certainly was loving, but that her good was not in fact attained, and so a real relation (that is, of the mode "actual") of loving did not occur. In other words, a loving relation of "representing" obtained from me to her, but no attribute in her was present to determine the relation, and so it was merely virtual, not actual love.

If the reader is in any further doubt that a passive term of "hospitality" is necessary for real relations of love to arise, consider times when one has been sincerely loved in ways that were unintentionally harmful. In such cases, the lover's acts are surely "loving" in a certain sense, since they are acting for the good of another. But equally, there is an obvious sense in which one is not loved but harmed. To put this definitionally, if love is ordered to the Good, then if someone were sincerely to "love" by imposing discipline so severe as to be traumatic, then the receiver of the discipline is not loved but is instead traumatized. This is true even if the misguided lover is loving sincerely. Hence, in order for a real relation of loving to arise, the beloved's good must actually be attained.

I take it to be self-evident that my sacrifice of time for the good of my wife meets the definition of "kenotic," but to bring out more clearly the nature of the passive role of "hospitality" as equally kenotic, consider a further example. You are drafted into the military for a war. The military thus designates you a soldier. If you were to accept the designation, you would exercise hospitality: you are welcoming a relation which strips your being of indefinitely many other potential roles (lawyer, priest, parent, etc.). The respect in which this is a stripping away of potentialities would be especially clear if you had an interest in a different potentiality - and especially if you did not believe in the war. Nonetheless, your being designated is not a "sacrifice" in the same sense as the active role is, since 
strictly speaking you are not actively giving up any potentialities. Rather, you are passive to the action of an external entity, which designates you a soldier by virtue of attributes of your person, like possessing legal status, age and citizenship. No action on your part is required to possess these attributes, and thus no action is required to be designated a soldier; your being determines the relation passively.

To clear up a potential source of confusion, when it comes to answering the call and taking up arms, action on your part is of course required, but this is consequent upon the designation, which has legal force independently of your subsequent actions. This is clear from the fact that you would not (typically) be answering a call if you were not designated a soldier; but once designated, you are then free to play an active role by taking up arms or by objecting. Contrastingly, in situations where you voluntarily become a soldier without being conscripted, then you would be the active party, not the passive party, and your role in the relation would therefore not be one of hospitality or "determining," but of self-sacrifice or "representing."

As such, kenosis is present in both roles, because whether actively being selfsacrificial, or passively being hospitable, a stripping away of possible ways of being occurs. To be caught up in a relation of love - or of conscription, or indeed any relation at all - is to undergo modal filtering, that is, to exchange a rich array of possibilities for a limited, determinate actuality. This filtering I define as "kenosis" henceforth.

Now if you accept the earlier thought experiment about universes as being fundamentally relational, and the more granular model given of the functioning of relations, then it would follow that "self-sacrifice" and "hospitality" are anthropomorphic forms of the universe-wide roles of "representing" and "determining" in which the being of everything in the universe manifests kenosis. After all, to be conscripted is plainly to be the terminus in a relation of conscription, in which your designation as a soldier is signified, and so some of your attributes (e.g. suitable age, your giving consent) serve to determine the relation. Likewise, my washing the dishes founds a relation signifying love for my wife, and so the sacrificial act of washing represents the respect in which my wife is beloved. 
As such, all being - and all experience - can be said to manifest kenosis, pervasively, in a manner analogous to acts of "self-sacrifice" and "hospitality," specifically, in acts of representing and determining.

\section{God is knowable speculatively to be kenotic and triadic}

Now in the Christian tradition, God is understood on philosophically speculative grounds to be trinitarian and kenotic. To give examples: God as Trinity is subsisting relations. ${ }^{36}$ The Spirit "proceeds from" the Father; ${ }^{37}$ a triadic relation of love characterises the trinitarian relationship. ${ }^{38} \mathrm{Christ}$ is "the exact representation of [the Father's] being." ${ }^{9}$ Christ is God embodied in human form. God speaks the universe into being. Jesus is "the kenosis" 40 - the most perfect expression of the self-sacrificial love

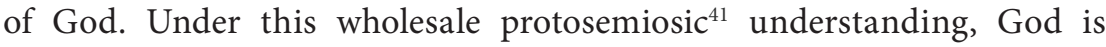
unequivocally understood as the very essence and source of kenosis. Moreover, God is understood to be triadic and to pervade the universe, and so Christians would most likely be delighted to find confirmation of these non-testable ideas in the empirical phenomenon of relating, which manifests kenosis at every moment and every scale of the universe, ${ }^{42}$ and is by nature amenable to the scientific method of obtaining knowledge.

We now have the materials to mount an empirical proof of divine action.

36 Thomas Aquinas, Summa Theologiae, edited by Roberto Busa. Vol. 2 (Stuttgart-Bad Canstatt: Frommann-Holzboog, 1980). Q. 27-43.

37 John 15:26 (NASB).

38 Augustine of Hippo. De Trinitate libri XV. Vol. L \& La VII, in Corpus Christianorum Series Latina, edited by W. J. Mountain and Francois Glorie (Turnholt: Brepolis, 1968), 9.1.1.

39 Hebrews 1:3 (NASB)

40 Philippians 2:7 (NASB).

41 I owe the notion (and the term) "protosemiosic" to John Deely's exploration and systematisation of philosophical history in terms of the development of the understanding of signs. C.f. John Deely, Four Ages of Understanding (Toronto: University of Toronto Press, 2001).

42 This remark is not intended in support of pantheism; the omnipresence of a theistic God implies pervasion of the universe. 


\section{Proof of experience of the trinity as kenotic}

I have promised empirical verification and not a merely speculative idea. What is required, therefore, is a manner of checking or testing whether this idea actually obtains in experience, and, furthermore, in a publicly verifiable way.

\subsection{What is to be tested}

What requires testing is a causal relation of divine action, specifically one where God "determines" the universe (or some part of it), and it "represents" God, from which it would follow that "founding" obtains between the universe and God, so that it can embody God whenever it signifies God to an interpretant. I have claimed that the universe does so most fundamentally in the very nature of real relations, which constitute the universe pervasively and manifest kenosis and triadicity. ${ }^{43}$

\subsection{The indifference of sign relations to the modalities of their terms}

But in order to be adequate, my proposed causal mechanism must support a (seemingly impossible) causal relation between contingent empirical events and a necessary, eternal being, known nonempirically through speculative exercises of reason or through trusting the testimony of figures in the Christian tradition. I am not, however, required to prove God exists (that is the work of the cosmological argument, perhaps). On the contrary, the potential nonexistence of God demonstrates the adequacy of sign action as a causal model. First off, my hypothesised relation is founded upon the kenotic and triadic attributes of directly experienced real relations and terminates at God's speculated trinitarian and kenotic nature. Now some signs are virtual, that is, they really signify though their termini do not exist. Recall the example of my being your dead brother: by no longer existing, I no longer determine the fundament, but the fundament still

43 If real relations constitute the universe pervasively, and if all real relations are claimed to manifest God's nature, then it follows that that things which are not typically understood as good and/or are not typically ascribed to God by theologians must be ascribed to God in the view advanced in this essay. This, however, is a relatively familiar position to be in - one which more traditional theologies find themselves in when asserting God's omnibenevolence, omnipotence, and the reality of evil. Namely, the scenario evokes the problem of evil or suffering. I address this in another paper, Arlyn Culwick, "A Theodicy of Kenosis: Eleonore Stump and the Fall of Jericho" (2019). 
represents the terminus. Since I - the "material" terminus in scholastic parlance - am absent, it now respects me merely "formally." This merely formal terminating of a relation is sufficient for you to continue to signify me as your brother.

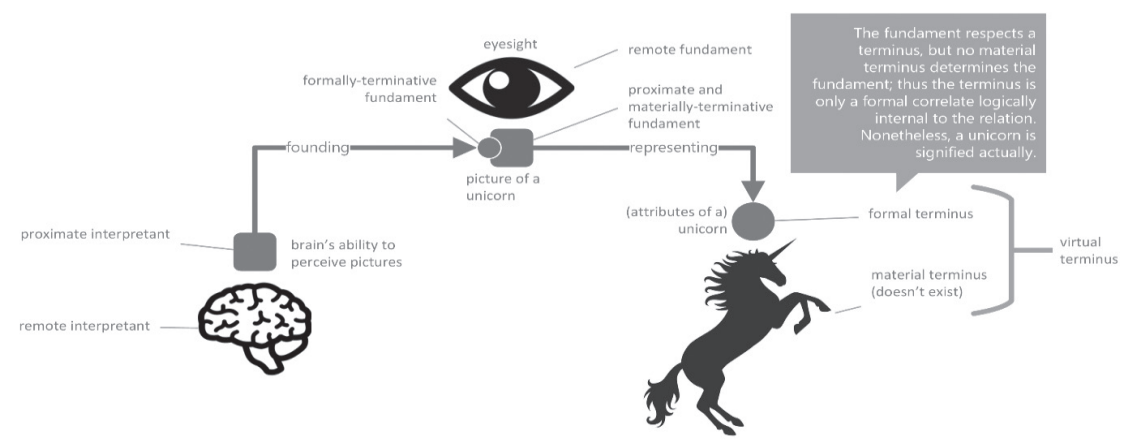

Identically, if God were not to exist, the kenotic and triadic nature of real relations would still signify God's nature. From this it follows that the relation is indifferent to the modality of its terms, because it obtains independently of God's modality as real or unreal. On this ground, therefore, sign action is adequate to model divine action.

To be clear, I am of course not arguing that divine action can occur on the ground that God is not necessarily assumed to exist. Rather, I am simply demonstrating the indifference of signs to their terms' modes, which, as noted in the introduction to this article, is a necessary property of a causal model that must relate a modally distinct cause and effect.

\subsection{God as terminus does not compromise God's pure actuality}

The above is insufficient on its own to account for divine action; as observed in the introduction, for my hypothesis to be adequate, it must also avoid requiring that a necessary being, who is pure act, involve any potentiality. Now my causal model commits me to the thesis that God exercises extrinsic formal causality in determining a fundament. As introduced above, to determine a fundament is to delimit ways in which things can relate to you. To "determine," therefore, is not accomplished by 
entering a contingent successive sequence, but purely by existing. ${ }^{44}$ From this it follows that for God to be embodied in the universe, it is not required that he participate in contingent movement from potency to act. It suffices for God to be. Therefore, attributes of a theistic God, like eternality and simplicity, remain uncompromised by my causal model. ${ }^{45}$

44 That is, to specify extrinsically and formally, it suffices simply to exist. Poinsot makes this point in many contexts in Book 1, Question 4 of the Tractatus, and perhaps most germanely on page 172 where he states: "[t]o move in the manner of an agent ... which pertains to the order of a producing cause, ... is distinguished from a movement in the manner of a stimulus object, which is reduced to the category of an extrinsic formal cause, a cause consisting in nothing but the fact that some power, in order to elicit an act of such or such a kind, needs to be actuated or ordered relative to an extrinsic object".

45 From this, the further question arises how the universe might be caused to exist, since, as Poinsot emphasises in Book 1, Question 4, objects do not cause existence, but specification. I note firstly that this question is a speculative one, and so is beyond the bounds of knowledge, and I am not required to pursue it in a essay concerned only with empirical verification. Secondly, this question invokes a highly speculative domain in which we must employ, throughout, mere analogies drawn from experience. Here I am thus free to speculate that "specification" operates at a higher modality than the manner relevant to Poinsot's concern. In comparison to contingent existence, in which existence is derivative and a composite of actuality and potentiality, God's necessary existence is pure actuality, and I suggest that here there would be no distinction between existence and specification. Hence, in the case of divine action, "specification" does not obviously imply a mode of causation lesser than causing to exist.

Furthermore, perhaps (for we are on permanently speculative ground here) a stronger light might be shone on the notion of "creation-by-mere-specification" by pursuing further the idea of God as eternal kenotic sign relations. Under such this model, the subsisting relations of the Trinity would be autopoietic, as signs are, generating a semiosic web through the causality of mere extrinsic formal specification (as signs do). Now even in scientific contexts, the efficient or agent cause traditionally taken to be required for existence appears as an epiphenomenon, or perhaps a higher order causal mode than the more general one of extrinsic formal specification - as Powell observes ("Epistemology's Minimal Cause as Basis of Science", 186). That is, matter reduces eliminatively to form under the rationale of sign action (for further discussion of this matter see "Machine code for the universe"). As a result, efficient causes are this same autopoietic generativity of signs, but taken (myopically) as an efficient cause, since the perspective taken focuses upon the (epiphenomenal materiality of the) sign's terminus only, not the whole sign relation.

Hence, contingent existence, seen as the effect of efficient causes, is just subsisting relations viewed (misperceived) as material objects. In contrast, the formally correct way to understand our existence would be as termini signified by trinitarian kenosis, where God is the interpretant who sees the Son as the lover and ourselves as beloved. In any case, on grounds presented in this essay and more fully in (ibid.), I believe that "mere specification" is empirically knowable to account for how things come to exist, and so can unproblematically be extended to the speculative domain of theology, and, moreover, without first requiring the traditional recourse to mere analogy. 


\subsection{Identifying a suitable test}

Now that my hypothesis has been qualified, the task is to identify an outcome that would confirm it experimentally. Powell observes that scientific tests always rely on an outcome that can, firstly, be privately and directly experienced by the experimenter, whose response, secondly, must be capable of being understood by others in the scientific community. Thirdly, at least some possible response of the experimenter must permit the scientific community to either falsify or confirm the theory. ${ }^{46}$ The experimental confirmation or falsification attained, however, is a highly qualified thing. No scientific test pretends to reveal the whole truth; all that is sought is the definitive identification of a real relation, not the intrinsic nature of anything. Neither is it established that the way in which a theory attains the real relation is itself real (e.g. the wave function enables us to predict with essentially perfect accuracy the behaviour of fundamental particles, but there is no experimental confirmation that the wave function is itself physical). By extension, a proof of divine action would not necessarily verify that signs have the many abstract attributes introduced in this essay (although of course it is possible that an experimenter may succeed in testing for these directly). Rather, theories are established (provisionally at best) by abductive inference to the best explanation, on the basis of a publicly verified real relation.

To identify a real relation, Powell observes that whenever some truth is confirmed, what in fact occurs is that people become capable of experiencing a new distinction between real and unreal relations. It is "the contrast between irreconcilable beliefs with replicated data [that marks] the usual path of scientific progress." ${ }^{47}$ An example he gives of this is that people hold differing views about real relations in society, like those "about relations of management and labour, or rich and poor, and of the well-educated and the poorly educated." ${ }^{48}$ Suppose that for one group, loyalists, "these real relations, sanctioned by our legal system, are seen as

46 Ralph Austin Powell, Freely Chosen Reality (Washington D.C.: University Press of America, 1983), interpreting Willard van Orman Quine. Theories and Things (Boston: Belknap Press of Harvard University Press, 1981).

47 Powell, "Epistemology's Minimal Cause as Basis of Science”, 187

48 Powell, Freely Chosen Reality, 92-93. 
inequalities inevitably resulting from the functioning of a free society." ${ }^{49}$ However, another group, deviationists, hold that at least a good part of these relations till now sanctioned by American law and taken for granted in American life should no longer be tolerated. Real relations long identified with legal order they now declare to be devoid of true legality. [That is, the] existing system of real relations is seen [to have merely] spurious and unreal legality. ${ }^{50}$

From this it can be seen that the two groups' differing views hold for the same underlying real relations of wealth inequality, education, and so forth. But in the absence of the deviationists or other contrasting views, it would not be possible to differentiate the real relations from the mere views ("theories" as I have called them) or unreal relations of the loyalists, because without contrasting views, the revealed difference between real relations and unreal views would not be experienceable. ${ }^{51}$ And in the presence of contrasting views, each view can now be freely identified with the real relation. This is why the deviationists' activism consists in identifying their view with the underlying real relations, precisely in order to differentiate real structural inequalities from unreal views codified in law. It is this identification and differentiation that makes it possible to experience them as distinct objects for the first time.

Along these lines, my hypothesis would be confirmed if we can distinguish and identify two contrasting ways of experiencing the world with an underlying reality. Two views suggest themselves: one is the experience of the world embodying God's kenotic and trinitarian nature, and the other is the typically modern experience of the world as reducing ultimately to "things in themselves." The first view is expressed beautifully by the Orthodox theologian Fr. Alexander Schmemann, in his celebrated book of sacramental theology For the Life of the World:

The first, the basic definition of man is that he is the priest. He stands in the center of the world and unifies it in his act of ... both receiving the world from God and offering it to God - and by

49 Ibid., 93.

50 Ibid., 93.

51 Ibid., 93. 
filling the world with this eucharist, he transforms his life, the one that he receives from the world, into life in ... communion with [God]. The world was created as the "matter," the material of one all-embracing eucharist, and man was created as the priest of this cosmic sacrament. ${ }^{52}$

As you can observe, Schmemann's vision is of a universe continually transformed from being merely "in itself" to being ordered to God, yielding a world and a humanity pervaded, shot through, with God's nature, not simply symbolically but in an embodied way.

At odds with this notion is - if you'd permit a sweeping generalisation the philosophically modern era. Perhaps the nominalistic central thread of this era is not embodiment but a quest - so far, a hapless one - for some kind of absolute ground for reality and experience, something non-mediated, non-relative, but simply itself. The "matter" that Schmemann refers to is reduced, under a modern rationale, to things with a mere intrinsic nature, which can be nothing but themselves, individual and self-contained.

To most contemporary readers, the former view will be analogous to that of the deviationists in Powell's example, since both are less-familiar views which serve to enable us to distinguish the latter, more familiar, view from an underlying reality that, to most moderns, is indistinguishable from it. But upon the discovery of Schmemann's view, we become capable of contrasting two views, which then avails us of many points of difference between them. Now if we are able to test empirically whether any one of these points of difference falsifies or confirms one of the views, then we have a "proof." As stated, this would not be a proof of the entire view, just a proof that one of the views signifies a real underlying relation, while the other fails to. (Usually, many such proofs are required to confirm an entire view.)

\subsection{Proof}

The seemingly impossible promise I have made is to provide an empirically testable theory, not a proven theory (though I will provide the beginnings

52 Alexander Schmemann, For the Life of the World: Sacraments and Orthodoxy (New York: St Vladimir's Seminary Press, 1973), 15. 
of that too). Now to prove that the theory is testable, I could provide at least one empirical confirmation of its truth, and in so doing support an abductive inference in its favour. And so here is a confirmation:

The failure, over 450 years, of the philosophical moderns to come to even loose consensus about a metaphysics, an ethics, or a philosophy of science is inductive evidence for the unreality of the modern experience. Most proximate is the historical failure to solve the "problem of the external world." That is, common human experience is of a real world, yet we see the classical moderns founder as they oscillate away from scholastic moderate realism to idealism, to empiricism, to rationalism, positivism, and so forth, lacking, at every turn, the theoretical tools to enable them to tell on the basis of experience if something has a nature independent of experience, thus establishing realism. We see, furthermore, the fruits of this failure, in that "philosophers" are typified in popular literature by aporia, ennui and detachment from lived experience. In any case, the problem of the external world is unsolved within philosophical modernity.

In contrast, you, the readers of this essay, have been provided with the materials to experience for yourselves how signs really embody their objects (for example, the case of experiencing a glass of water), in a manner supporting Schmemann's view, which I have qualified as kenotic. You have only to think through the mechanism of sign action and to directly experience it occurring (in this case, by picking up a glass of water) in order for the materials for a true proof to become available. Specifically, in picking up a glass of water, we not only experience our here-and-now relating to the glass, but we may simultaneously experience ourselves indirectly experiencing the glass itself, that is, through the mediation of our relations to it. That is, we immediately experience the distinction between our direct relations to the glass and our indirect experience of the glass itself.

Now if we only experience directly our relation to the glass, then this experience is not of the glass itself, and so we do not come to know its intrinsic nature. Thus, what we might take to be its nature is in fact only whatever we can infer from our relation to it, and so our experience of the 
glass's nature is at least partially constructed or unreal ${ }^{53}$ (even though we are assured of our really relating to it). Hence, in addition to experiencing real relations, we additionally experience an unreal relation to the glass, in the awareness that our experience of its nature is at least partially constructed. As a result, we directly experience a distinction between a real and unreal relation.

Following Powell, the theory thus qualifies as testable on experiential grounds. What follows is its confirmation. (Those seeking to validate further the theory in the abstract (not as directly experienced) may consult Poinsot, ${ }^{54}$ Powell, ${ }^{55}$ and my expanded treatment of this subject. ${ }^{56}$ )

By directly experiencing relating to a glass of water in the here-and-now, we may proceed to (a) distinguish our experience of the real from the unreal views of modernity and of the semiotic view given in this article, (b) make an abductive inference (an inference to the best explanation), falsifying the modern view on account of its historical failure to articulate experience of the real, and (c) identify the semiotic view with our direct experience of the real, on account of its ability to unearth the direct experience of the distinction between real and unreal relations, thus serving to enable us to know the real. (d) We may then note that this article is a public

53 My understanding of "real" and "unreal" conforms with a common-sense opposition of these terms (for example, horses are real, but unicorns are unreal). However, given that the modes have been introduced in a previous section, some elaboration of underlying complexities is perhaps of value here.

In the example of a glass of water, the glass is real, but if we erroneously assume that our directly experienced relation to the glass is the glass, then we have formed an unreal object (or at least a partially unreal one). It is unreal because the relations taken to be part of the intrinsic nature of that glass are taken to be material termini, yet they are relations, not material termini, and so this confused relation of cognition lacks a material terminus and is thus virtual.

That said, it remains true that the modes (virtuality, potentiality, actuality) are all modes of the real. This is the case because of the real effect operative in virtual signs, and because of the real potential for relation in potential signs (e.g. the potential energy of a rock perched on a hill). However, the reality of the modes does not suffice to render an erroneous perception a perception of something real; it only suffices to render the virtual sign real in its effects - the relation to the terminus is not itself virtual, it simply is nothing.

54 Poinsot, Tractatus de Signis.

55 Powell, Freely Chosen Reality.

56 Culwick, "Machine code for the universe." 
object confirming an experimental outcome that each of its readers have independently experienced, and thus who may now independently signal that they have replicated this article's results. As per Powell's method, this establishes the proof as a publicly verified reality, not just a private experience. ${ }^{57}$ It is now a properly scientific proof. (e) Finally, we import the merely speculative and essentially perfectly protosemiosic notions that God is kenotic, triadic, and that his nature pervades the universe - and identify this with the publicly verified reality of sign relations, such that God's nature and action is directly experienced in every possible experience of the universe. As such, my hypothesis is confirmed.

\section{Bibliography}

Aquinas, Thomas. 1980 (c. 1266/73). Summa Theologiae. Edited by

Roberto Busa. Vol. 2. 7 vols. Stuttgart-Bad Canstatt: FrommannHolzboog.

Augustine of Hippo. 1968 (399 and 422/6). De Trinitate libri XV. Vol. L \& La VII, in Corpus Christianorum Series Latina, edited by W. J. Mountain and Francois Glorie. Turnholt: Brepolis.

Culwick, Arlyn. 2019. “"Machine code for the universe:” how the action of signs pervades everything." Academia.edu. 17 03. [Online]. Available: https://academia.edu/39709311/_Machine_code_for_the_universe_-_ how_the_action_of_signs_pervades_everything [Accessed: 14 July 2019].

- 2019. "A Theodicy of Kenosis: Eleonore Stump and the Fall of Jericho." Academia.edu. 20 07. [Online]. Available: https://www.academia. edu/39880116/A_Theodicy_of_Kenosis_Eleonore_Stump_and_the_ Fall_of_Jericho [Accessed: 13 July 2020].

Deely, John. 2001. Four Ages of Understanding. Toronto: University of Toronto Press.

Deely, John. 1994. “The Grand Vision.” Transactions of the Charles S. Peirce Society 371-400.

57 Powell, Freely Chosen Reality, 65. 
Dodds, Michael J., O.P. 2000. “The Doctrine of Causality in Aquinas and The Book of Causes: One Key to Understanding the Nature of Divine Action." Jacques Maritain Center: Thomistic Institute. Notre Dame, Indiana, 14-21 July. [Online]. Available: https://maritain.nd.edu/jmc/ ti00/dodds.htm\#N_22_[Accessed: 13 July 2020].

Fogelin, Robert. 2003. A Defense of Hume on Miracles. Princeton and Oxford: Princeton University Press.

Garret, Don. 1997. Cognition and Commitment in Hume's Philosophy. New York and Oxford: Oxford University Press.

Hawking, Stephen. 1988. A Brief History of Time: from the Big Bang to Black Holes. New York: Bantam Books.

Hume, David. 1999 (1748). An Enquiry Concerning Human

Understanding. Edited by Tom L. Beauchamp. Oxford: Oxford University Press.

1995 (1960). New American Standard Bible. Nashville: World Publishing.

Peirce, Charles. 1866. Lowell Lectures on The Logic of Science; or Induction and Hypothesis: Lecture VII.

Peirce, Charles Sanders. 1994 (1958-1966). The Collected Papers of Charles Sanders Peirce. Electronic Edition. Edited by Charles Hartshorne and Paul Weiss. Cambridge, MA: InteLex Corp. [Online]. [Accessed: 6 September 2018].

Pinsent, Andrew. 2012. The Second-Person Perspective in Aquinas's Ethics. New York: Routledge.

Poinsot, John. 1985 (1632). Tractatus de Signis. Edited by John Deely and Ralph Austin Powell. Berkeley: University of California Press.

Polkinghorne, John, ed. 2001. The Work of Love: Creation as Kenosis. Grand Rapids, Mich.: Wm. B. Eerdmans Publishing Company.

Powell, Ralph Austin. 1989. “Epistemology’s Minimal Cause as Basis of Science". Edited by Terry Prewitt, John Deely and Haworth Karen. Semiotics 1988. New York: University Press of America. 180-188. 
—. 1983. Freely Chosen Reality. Washington D.C.: University Press of America.

Powell, Ralph Austin. 1986. "From semiotic of scientific mechanism to semiotic of teleology in nature." Semiotics, 296-305.

Quine, Willard Van Orman. 1981. Theories and Things. Boston: Belknap Press of Harvard University Press.

Ryle, Gilbert. 1949. The Concept of Mind. Chicago: University of Chicago Press.

Schmemann, Alexander. 1973. For the Life of the World: Sacraments and Orthodoxy. New York: St Vladimir's Seminary Press.

Special Divine Action Project. 2020. Influence Map. [Online]. Available: https://sda.bodleian.ox.ac.uk/sda/\#!/influence-map/ [Accessed: 15 July2020]. 



\title{
Articles • Artikels
}

\author{
IV. Gender \& theology
}

